\title{
SANTOS, Boaventura de Sousa, Epistemologies of the South: justice against epistemicide. London: Paradigm Publishers, 2014. 240p.
}

\author{
Wanda Capeller \\ (Tradução Ivan Capeller)
}

\section{UMA EPISTEMOLOGIA DOS OPRIMIDOS}

Considerado um dos mais importantes sociólogos do direito contemporâneo, Boaventura de Sousa Santos é um pesquisador globe-trotter que busca em países longínquos o material para suas reflexões. Sua última obra, Epistemologies of the South: justice against epistemicide, testemunha sua capacidade de nos abalar, sobretudo a nós, pesquisadores dos países do Sul, com os quais ele se engaja sem hesitação.

O livro se inicia com quatro textos "preliminares": um "Prefácio do autor", um "Manifesto pelo bem viver" (p. 2), um "Manifesto pelo intelectual ativista" (p. 3-17), e uma "Introdução" (p. 19-46). Esses documentos iniciais lançam as bases de uma partida a ser progressivamente jogada, cuja meta será a recusa de se conformar com as epistemologias do Norte, tendo em vista a redescoberta daquelas, esquecidas, que emergem do Sul. Seguem-se oito capítulos perturbadores que atacam ideias preconcebidas e se constituem, no conjunto, em uma espécie de manifesto científico do autor. No "Prefácio", três ideias anunciam os fundamentos deste livro: a de uma apreensão do mundo para além de uma compreensão puramente ocidental; aquela segundo a qual não existe justiça social global sem uma justiça global cognitiva; e aquela que afirma que as transformações emancipatórias do mundo devem seguir gramáticas distintas daquelas que são desenvolvidas pela teoria crítica do "Ocidente eurocêntrico".

Segue-se um "Manifesto pelo bem viver", que reivindica um lugar para aqueles que, sem rosto nem voz, são sacrificados pela voracidade do capitalismo, do colonialismo e do patriarcalismo (p. 2); e um "Manifesto pelo intelectual ativista", que denuncia a impossibilidade de um pensamento verdadeiramente radical no "Norte global", gerando uma dupla opacidade: as ideias radicais não se traduzem em práticas radicais (e vice-versa), e estas últimas não se reconhecem nas ideias radicais que estão à sua disposição. A astúcia da modernidade ocidental reside na permissão aos intelectuais de produzir ideias revolucionárias no interior de instituições reacionárias (p. 3). Porém, em sua busca por alternativas, o intelectual ativista se encontra limitado pelos perigos da impossibilidade de comunicar o indizível e da impossibilidade de falar a várias vozes. A primeira concerne um mundo de paixões, intuições e mitos, que se encontra fora da racionalidade da ciência moderna; a outra questiona o ativismo intelectual a partir da experiência vivida pelo próprio Boaventura de Souza Santos, notadamente no Fórum Social Mundial e no seio das comunidades indígenas da América Latina: como perceber a extensão das suas ideias em coletivos sem nome e sem contorno? 
Estamos, assim, diante de uma dupla "ausência": aquilo que só poderia ser formulado coletivamente e aquilo que não pode ser racionalmente formulado, nem individual nem coletivamente (p. 5-7). Escrever a partir da perspectiva da impossibilidade do radicalismo coloca inumeráveis questões - o que se quer? Onde vivemos? Que certezas nós possuímos? De qual tipo de saber nós dispomos? Como nós somos educados? Quais são as nossas armas? Com que aliados nós podemos contar? Como construir alianças? (p. 6-15). A tarefa a que se propõe o intelectual ativista é elaborar teorias capazes de conceber, na retaguarda, o que as teorias de vanguarda não conseguem, por não gostar de surpresas. Em outras culturas não ocidentais, vemos despontar, no campo político, experiências que escapam de caminhos já traçados (p. 11).

Na sua "Introdução", o autor marca a distância que existe entre a imaginação política do centro ocidental e a teoria crítica como ele a concebe. O Norte global se torna pequeno em termos econômicos, políticos e culturais, e não possui mais nenhuma lição a dar ao Sul global; muito pelo contrário, tem de aprender com este último, mesmo que, em razão dos colonialismos, tenha perdido a capacidade de reconhecer a existência de outras histórias além daquelas relativas ao Ocidente (p. 19). Boaventura Santos analisa aqui as dificuldades crescentes desses últimos 30 anos, desprovidos de alternativa aos repertórios políticos e com uma reduzida imaginação política emancipatória: diante das questões extremas que se colocam, só se produzem repostas fracas relativas "ao fim do capitalismo sem fim" e "ao fim do colonialismo sem fim" (p.19-27). Sua reflexão chega a problemas teóricos que levantam certos paradoxos, como o da urgência vs. mudança civilizatória, que se refere a temporalidades contraditórias relativas ao quadro de ação coletiva (p. 27 et seq.); ou, ainda, àquele das dificuldades com que se confrontam as teorias críticas eurocêntricas, igualmente ligadas a conflitos de temporalidade, orientados, dessa vez, no sentido da natureza das trajetórias de inovação política: a inovação mais recente ou aquela que reinventa o antigo. Aqui, o autor toma como exemplo o projeto Yasuní ITT, no Equador, que, em matéria energética, representa uma alternativa ao modelo de desenvolvimento extrativista atualmente dominante na América Latina, na África e, em geral, em todo o Sul global (p. 30 et seq.).

Assim, o autor denuncia a imaginação política ocidental por haver esgotado suas possibilidades de produção de trabalho crítico e de se apropriar de qualificativos como "democracia", "inclusão" e "desenvolvimento sustentável" para embaralhar as pistas, obrigando a teoria crítica a mobilizar de forma radical, para significar sua diferença, os termos "alternativa", "participação" e "democracia deliberativa" (p. 33). No entanto, a dificuldade última da teoria crítica eurocêntrica, que estabelece relações fantasmagóricas entre a teoria e a prática, concerne à discordância entre 0 que é afirmado pelas teorias e pelas práticas inovadoras. Com efeito, a cegueira teórica torna as práticas invisíveis e subteorizadas, e a cegueira da prática torna a teoria irrelevante (p. 35). O verdadeiro inimigo é o capitalismo neoliberal; é ele que intensifica os processos de exclusão, tanto nos países periféricos como nos países centrais. Se as lutas de resistência se reforçam, não sabem à qual inimigo se voltar: deve-se afrontar o capitalismo em nome do socialismo ou visar outras formas póscapitalistas que possuam um rosto mais humano? Permanece o fato de que as relações entre a teoria e a prática impedem o encontro de um consenso sobre a eficácia das políticas "transformadoras". Vimos que, a partir dos anos 1970, a crise da esquerda permitiu uma regressão da luta de classes em favor de uma virada identitária e cultural. Ora, este recuo em relação às formas clássicas de organização e ação políticas fez emergir novas formas de luta, como os movimentos dos 
indignados, mesmo que alguns se manifestem com um extremismo inconsequente (p. 36 et seq.).

Em "Modernidade centrífuga e Ocidente subalterno: graus de separação" (TDA), encontramos três capítulos decisivos: no primeiro, "Nuestra America. Identidades pós-coloniais e mestiçagens," Boaventura Santos apoia a ideia de um século XX com múltiplas facetas, notadamente aquela formada pela Europa-América, portadora de promessas de democracia e de bem-estar social, que, no entanto, conheceu guerras devastadoras e permitiu a instalação de um tipo de fascismo societal. Aquela, igualmente, da "Nuestra America" (título de um ensaio de José Martí, de 1891), defensora da não importação de modelos ocidentais e da criação autóctone de conhecimentos e formas de governo em sintonia com a realidade desse continente (p. 51 et seq.). Esses projetos, sempre atuais, fundamentam-se em uma maneira particular de viver, fazer e pensar, totalmente inadaptada aos institutionalismos e legalismos à revelia, pois apelam muito mais para a imaginação e o utopismo (p. 56). Ora, não se mudam os autores! Boaventura Santos reafirma aqui o seu lado visionário, presente em toda a sua obra e já notado em seu livro Vers un Nouveau Sens Commun juridique: droit, science et politique dans la transition paradigmatique, em que ele exigia que "não se atirasse no utopista" (cap. 8). E com razão. Diante dos estragos do neoliberalismo, a utopia ajuda a resistir.

Em Outro Angelus Novus: para além do jogo moderno das raízes e das opções (título que se refere ao comentário de Walter Benjamin sobre a pintura de Klee, Angelus Novus, p. 74), o autor se interroga sobre a capacidade das ciências sociais de tratar dos problemas fundamentais de cada época. Segundo ele, os primeiros decênios do século XXI testemunham a existência de uma linha abissal que divide as realidades sociais: de um lado, aquelas ligadas às sociedades centrais; e, do outro, grupos sociais cujos conhecimentos são invisíveis. Isso significa que o universalismo europeu, com a generalização das ciências sociais em paradigma da modernidade ocidental, ao postular uma tensão dialética entre regulação social e emancipação social, tentou demonstrar que, a cada crise de regulação social correspondia uma nova forma de emancipação social. Mas a experiência histórica revela que essa tensão dialética nunca existiu.

Caminhos e opções se abrem para esclarecer o leitor sobre uma questão fundamental: como reinventar a emancipação enquanto outra forma de regulação, sem que sua combinação seja nefasta? (p. 71 et seq.). No capítulo "Existe um Ocidente não ocidental?", Boaventura Santos afirma que uma parte do pensamento ocidental foi ignorada, notadamente aquela que não aderia aos cânones do capitalismo e do colonialismo. Então, ele revisita certos autores negligenciados para constatar que o "monopólio epistemológico" do Ocidente não se deu sem contradições (p. 99 et seq.). Sua hipótese básica é de que as teorias e as disciplinas deverão, a partir de agora, fornecer respostas não teóricas e não disciplinares a questões que elas mesmas não foram capazes de levantar (p. 107).

A segunda parte da obra, "Rumo às epistemologias do Sul contra o desperdício da experiência", começa com um capítulo intitulado "Para além do pensamento abissal", consagrado à visibilidade e à invisibilidade impostas às concepções radicais (p. 118 et seq.). Para o autor, o conhecimento e o direito representam as formas modernas mais acabadas de um pensamento abissal (p. 119), que delimitou as linhas de uma cartografia dual: a cartografia legal e a cartografia epistemológica (p. 123). Assim, do outro lado da linha abissal, encontra-se o domínio que se estende além da legalidade e da ilegalidade, da crença e da falsidade, da idolatria e da magia, um domínio que deságua em formas de ausência radicais, como a ausência de 
humanidade e as sub-humanidades modernas, não suscetíveis de inclusão social. Eis o lugar de negação de uma parte da humanidade, já que a humanidade moderna não pode ser concebida sem a sub-humanidade moderna (p. 123). Essas linhas abissais globais se movem, no entanto, na medida em que os povos submetidos ao paradigma da apropriação/violência se organizam para integrar o paradigma da regulação/emancipação (p. 124 et seq.).

O autor nos leva então "Rumo a uma epistemologia da cegueira", a partir da qual o projeto de modernidade ocidental se organizou em torno da discordância entre a experiência e a expectativa social. Esse projeto conheceu várias formas, notadamente o "conhecimento como emancipação" e o "conhecimento como regulação", um relativo à etapa de ignorância do "colonialismo", e o outro relativo àquela do conhecimento da "solidariedade". As duas formas de saber se equilibram entre si de modo dinâmico. Entretanto, um acidente histórico aconteceu, criando turbulências e reduzindo as possibilidades do paradigma da modernidade àquelas postas à disposição pelo mundo capitalista, provocando um desequilíbrio entre regulação e emancipação. Desse modo, a primeira canibalizou a última (p. 138-139). Não importa. Há uma "epistemologia da visão" cujas potencialidades se desenvolvem nos interstícios dos conhecimentos ligados à regulação e à emancipação (p. 156). Vemos surgir, então, uma das mais originais concepções de Boaventura Santos, sua sociologia das ausências e das emergências, fundada sobre uma premissa fundamental: a prática social é o conhecimento social (p. 157).

No capítulo "Uma crítica da razão indolente. Contra o desperdício da experiência e rumo à sociologia das ausências e à sociologia das emergências", o autor constata logo de início que a compreensão ocidental do mundo é parcial (p. 164 et seq.). Ele distingue então cinco lógicas subjacentes aos modos de produção da "não existência" de certos conhecimentos: uma relacionada à "monocultura e ao rigor do conhecimento"; outra que reside na "monocultura do tempo linear"; uma lógica das classificações, que constitui uma "monocultura da naturalização das diferenças"; uma lógica de produção da não existência, que se traduz por uma "monocultura da lógica das escalas dominantes"; e aquela, finalmente, que se manifesta em uma "monocultura da lógica de produção capitalista" (p.172-175). A sociologia das ausências opera no sentido da substituição das "monoculturas" pelas "ecologias", ou seja, a existência de saberes ligados à diversidade durável baseada em racionalidades complexas. Assim, a lógica da monocultura do tempo linear deve ceder o lugar a uma ecologia das diversas temporalidades (p. 176). Nesse contexto, a sociologia das emergências também encontra o seu lugar, mesmo se exige uma atenção especial, de caráter filosófico, pois ela se manifesta em um tempo por vir, substituindo o vazio do futuro (segundo a lógica do tempo linear) por possibilidades concretas que aparecem (p. 182). Além disso, a sociologia das ausências estende o domínio das experiências sociais já disponíveis, enquanto a sociologia das emergências estende o campo dos possíveis (p. 186).

No capítulo "Ecologia dos conhecimentos", Boaventura Santos reafirma suas ideias centrais sobre a ecologia dos conhecimentos e a sociologia das ausências, para mostrar que elas se confrontam sem cessar à monocultura do pensamento científico ocidental moderno. Este último, com efeito, ignora e desperdiça os saberes construídos em lugares distintos do mundo ocidental, em testemunho ao fato de que toda ignorância é ignorância de certo tipo de conhecimento, e de que todo saber é a superação de uma ignorância particular (p. 188). Para a ecologia dos saberes, no entanto, credibilisar os conhecimentos não científicos não significa desacreditar o saber científico. Ao contrário, faz-se necessária a utilização do saber acadêmico em 
um contexto mais amplo de diálogo com outros tipos de conhecimento, e é por isso que a ecologia dos saberes deve estar sempre relacionada à infinita diversidade do mundo da experiência (p. 188-191). O autor articula aqui uma reflexão sobre a ciência moderna e a ecologia dos saberes, que integra uma discussão acerca da pluralidade interna e externa das práticas científicas (p. 193 et seq.). Ele afirma que as abordagens interculturais e pós-coloniais reconhecem a existência de sistemas plurais de conhecimento, constituindo-se assim em possíveis alternativas à ciência moderna (p. 199). Esse capítulo se acaba com a apresentação de um estudo de caso na África (p. 202 et seq.) que leva a uma reflexão sobre uma "epistemologia pragmática", justificada pelas experiências vividas pelos oprimidos, e que, in fine, nos orienta rumo a um "conhecimento prudente" (p. 202- 211).

O último capítulo, "Tradução intercultural. Diferenças e compartilhamento con passionalità", estabelece como duplo marco das epistemologias do Sul a "ecologia dos conhecimentos e a tradução intercultural" (p. 212). É a esta última que o autor se dedica aqui. Ele mostra que no coração da ecologia dos conhecimentos encontra-se a ideia segundo a qual os diferentes tipos de saber são incompletos de diversas maneiras, que conduzem, não à busca da completude, mas a uma tomada de consciência da incompletude recíproca dos saberes. Essa tomada de consciência é uma condição preliminar à realização da justiça cognitiva. Assim, a tradução intercultural se torna uma alternativa à abstração do universalismo baseado nas teorias gerais produzidas pelo ocidental "etnocêntrico", o que remete à ideia da incomensurabilidade entre as culturas. Para Boaventura Santos, a noção de "tradução intercultural" é essencial para a reinvenção do mundo social e para a emancipação e a imaginação política rebelde. Do ponto de vista das epistemologias do Sul, essas traduções interculturais se combinam com traduções interpolíticas, a partir das quais se podem promover os intermovimentos políticos que constituem, hoje em dia, a fonte da globalização contra-hegemônica (p. 212-213).

Ao revisar os debates sobre traduções, traduções culturais e tradução como culturas, o autor destaca certos tópicos que lhe interessam, particularmente para fundar sua teoria das "zonas de contato traduzíveis": a linguagem, a noção de "traduzibilidade" ("translatability") - mobilizada por Walter Benjamin no sentido das "leis que governam a tradução" e que incitam a ver a diferença; ou, ainda, aquele relativo às assimetrias. Como essas assimetrias que se instalam no trabalho de tradução podem ser reduzidas ou eliminadas? (p. 216). O que a tradução permite é uma espécie de inteligibilidade mútua no seio de diversas experiências sociais culturalmente diferentes, algumas disponíveis, outras a reinventar. E tudo isso está em perfeito acordo com a sociologia das ausências e com a sociologia das emergências (p. 217), em seu movimento de ressaltar as epistemologias do Sul e permitir-lhes dar lições ao Norte (p. 222 et seq.).

Em sua conclusão, o autor afirma que, como já havia apresentado os problemas fundamentais da transição de paradigma do Ocidente em seu livro precedente, Vers un nouveau sens commun juridique, coube ao presente volume delinear os principais contornos dessa mesma transição em suas dimensões sociais, políticas e jurídicas. Nessa reivindicação de continuidade, há uma profusa renovação. Reconhecemos o trabalho de uma vida inteira. 